\title{
Sox13 is a Novel Marker for Hair Follicle Development and Differentiation
}

Mai Noto, Natsuko Noguchi, Motomu Manabe, and Shin-Ichi Osada

Department of Dermatology and Plastic Surgery,

Akita University Graduate School of Medicine, Akita, Japan

Conflict of Interest (COI) : No potential COI to disclose.

\section{Introduction}

The Sry-related high-mobility-group box (Sox) gene encodes a transcription factor family that plays crucial roles in the determination of cell fate and organogenesis') 2). Sox13, a group D member of the Sox family3), is expressed in various tissues such as brain, cartilage, hair, kidney, pancreas, liver, kidney and blood vessels. However, knowledge of the biological roles of Sox13 is largely limited ${ }^{4}$.

\section{The Sox Family}

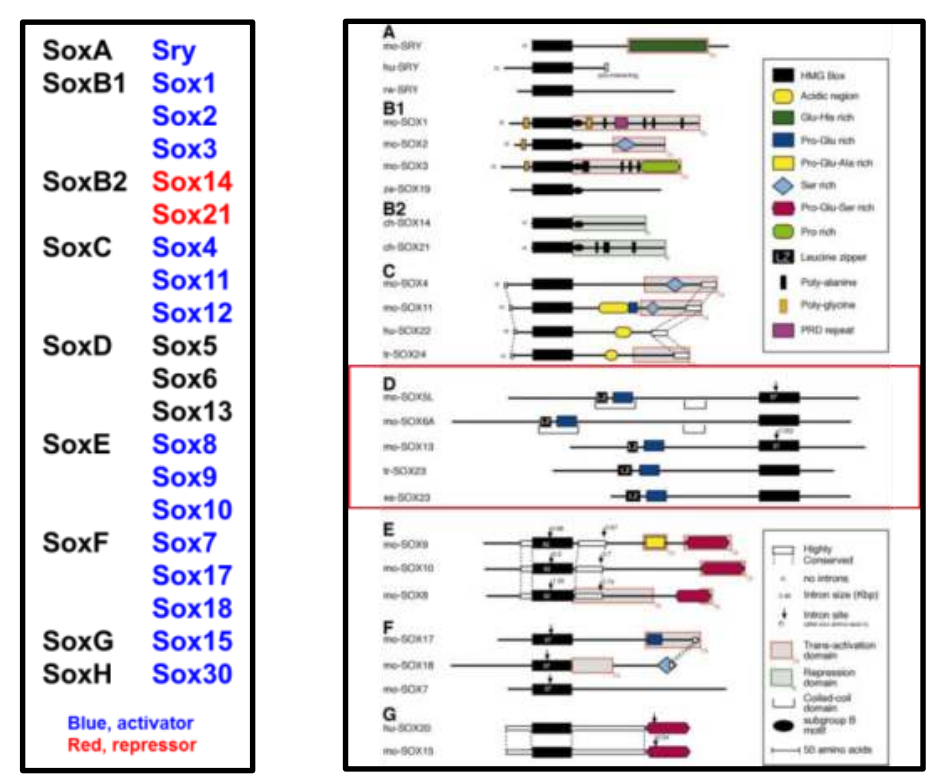

\section{Aims}

To examine the precise expression domains of Sox13 protein and its role in mouse development, we generated Sox13-LacZ-knock-in mice (Sox13LacZ/+), in which the Sox13 coding sequence was disrupted by an in-frame insertion of the $\beta$-galactosidase (LacZ) gene. Using the knock-in mice, we examined spatiotemporal expression patterns of Sox13 in the hair follicle and its role in hair development ${ }^{5}$ )

\section{Results}

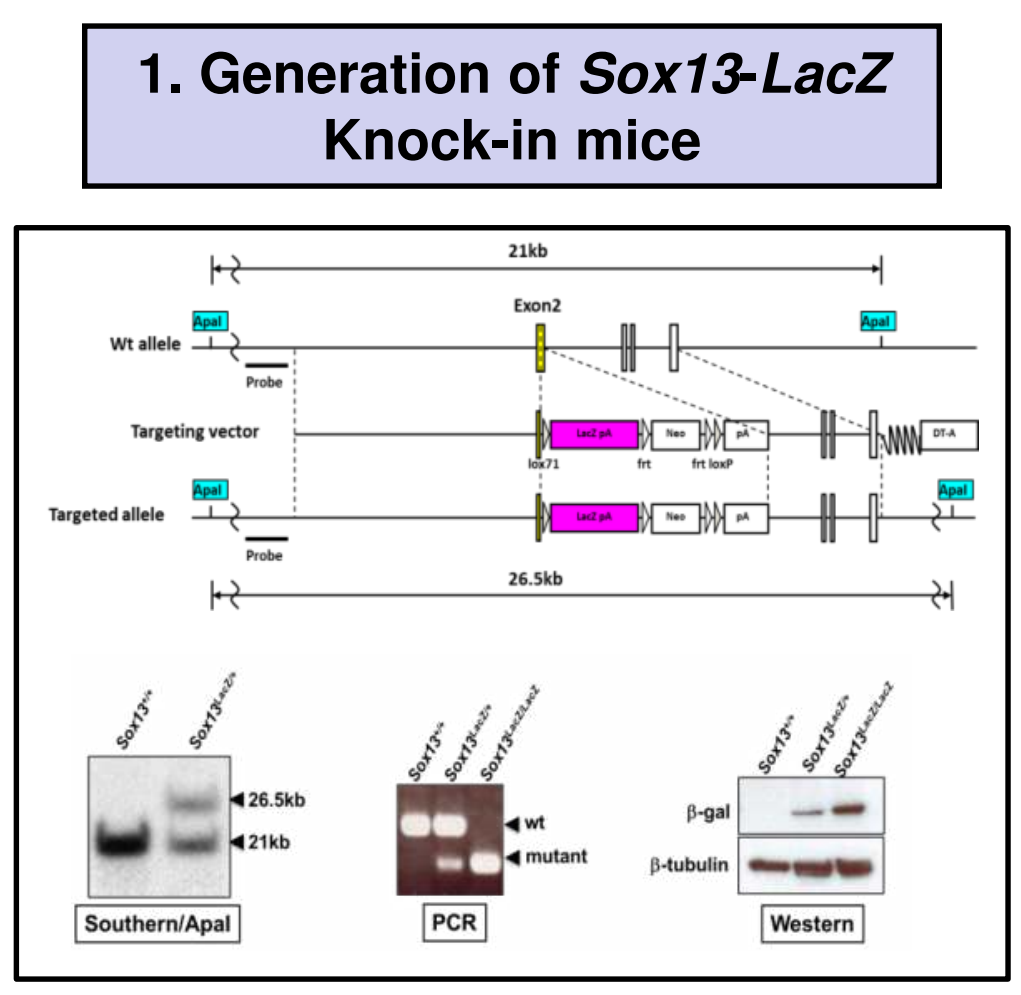

The targeting construct was designed to disrupt the Sox 13 coding sequence by introduction of the $L a c Z$ reporter in-frame into exon 2, which contains the translation initiation codon. We can analyze the expression of Sox13 by detecting $\beta$-galactosidase activation of $\operatorname{LacZ}$.

\section{Sox13 is Expressed in the Whisker Pad}

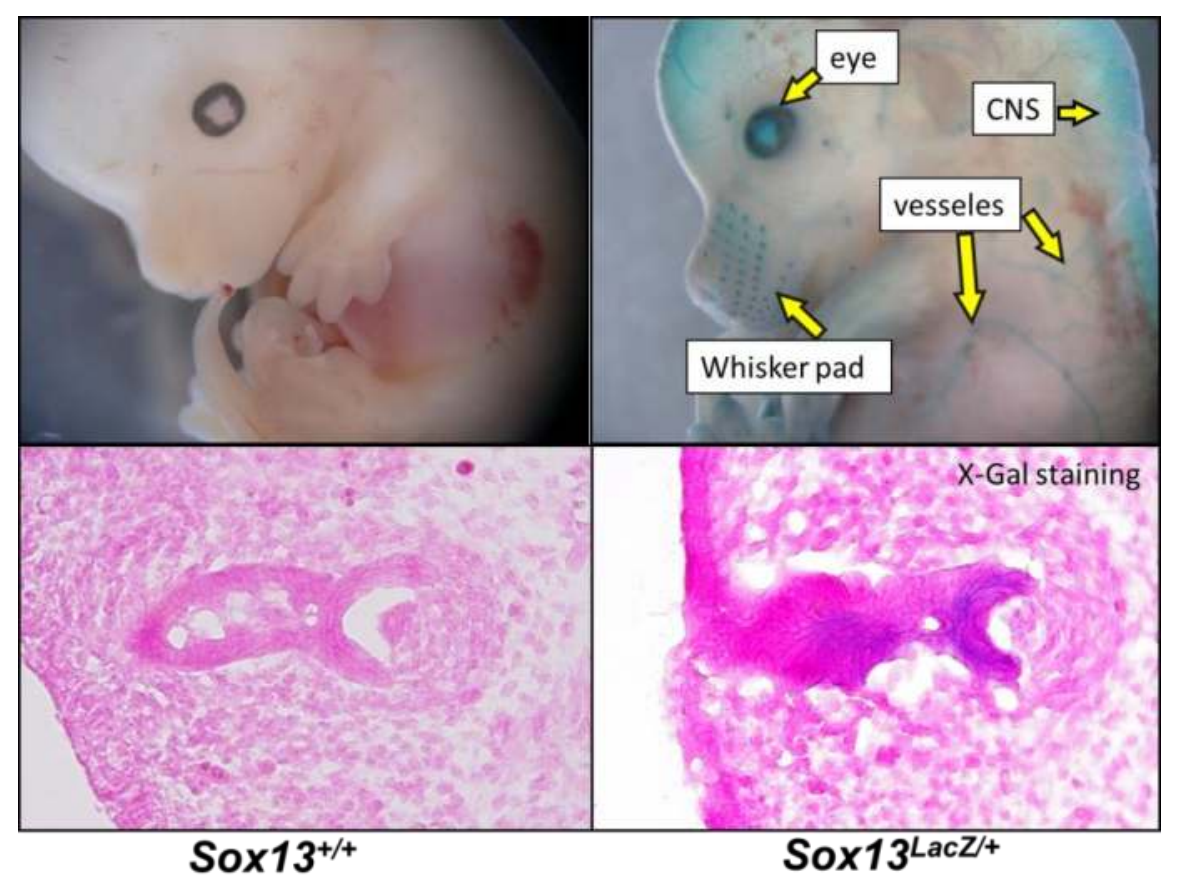

Sox13 was expressed in the whisker pad, eye, blood vessels, and neural tissues at E14.5. In the cross sections of the whisker pad, Sox 13 was expressed in the hair follicles of the vibrissae.

\section{Sox13 is Expressed in the Hair Germ}
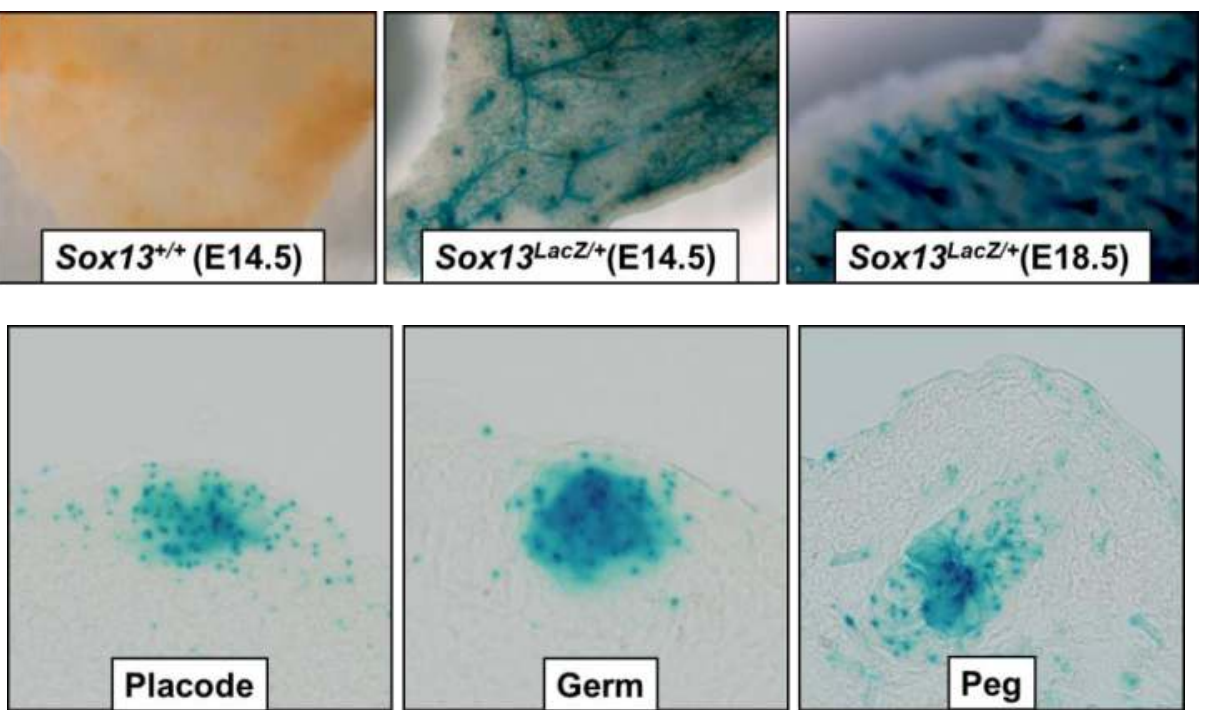

Sox13 was initially expressed in the epithelial portion of the placode (E14.5), and subsequently in the hair germ and the hair peg(E18) during hair follicle morphogenesis.

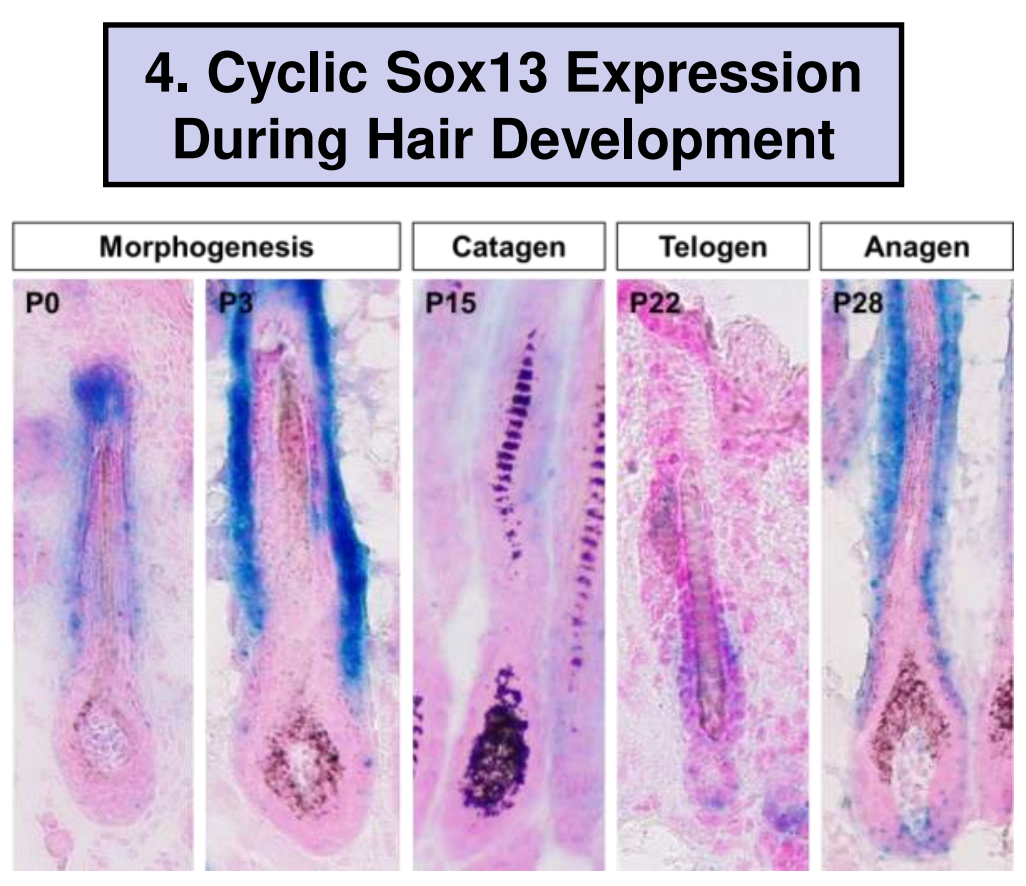

Sox13 was expressed in the epithelial sheath at birth (postnatal day 0; P0) and reached its maximum expression at P3-5. During catagen (P15), Sox13 expression in the epithelial sheath weakened. In telogen (P22), Sox13 became localized in the bulge and secondary germ regions, and in the following anagen (P28), strong Sox13 expression was again observed in the epithelial sheath.

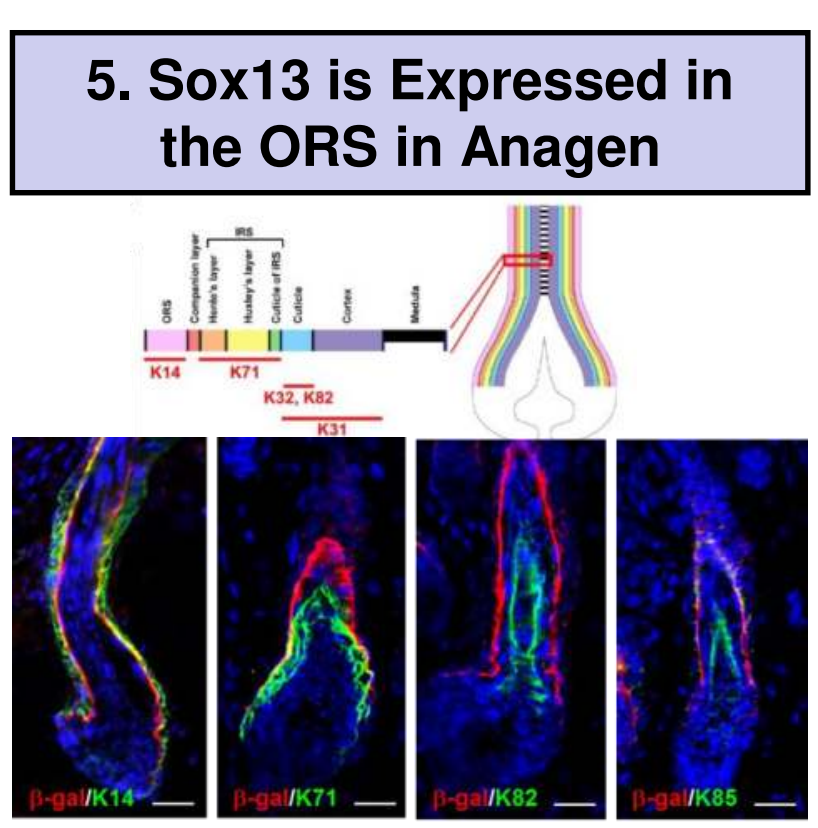

The expression domains of Sox13 were overlapped with those of keratin 14 (ORS marker), partially overlapped with those of keratin 71 (IRS marker), but not with those of keratin 82 and 85 (hair cuticle and cortex marker, respectively).

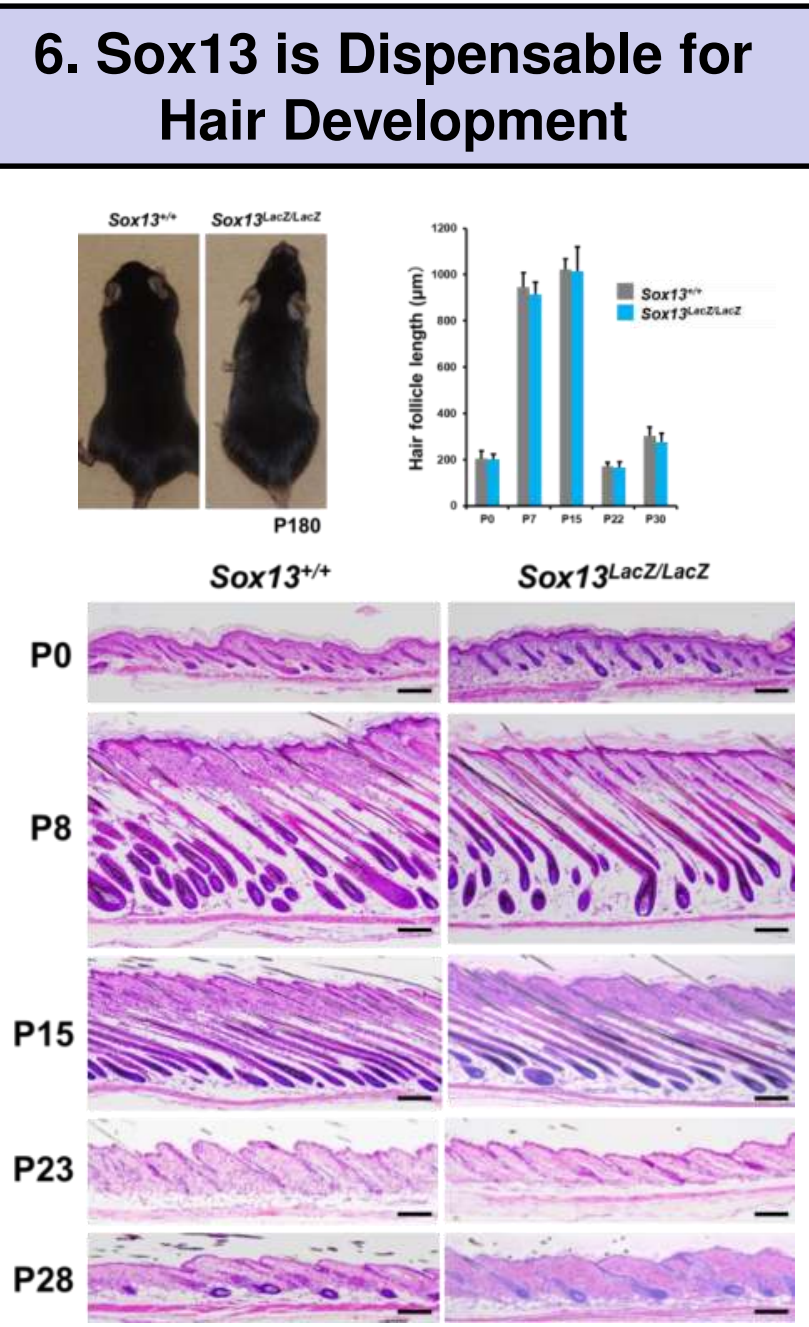

The integumentary structures of Sox $13^{\text {LacZ } / L a c Z}$ mice were grossly and histologically indistinguishable from those of control mice.

\section{Discussion}

Our results suggest that although Sox13 is dispensable for epidermal and adnexal development, Sox13 is a novel early marker for hair follicle development and differentiation. Because the expression patterns of Sox13 were coincident with those of Sox 96 ), it would be interesting to examine whether Sox9 and Sox13 form a heterodimer and the heterodimer is involved in hair follicle development and specification of hair follicle stem cell. The role of Sox13 in skin tumorigenesis is an intriguing topic for future investigation. Recent studies demonstrated that Sox9 is a downstream target of Hedgehog signaling, which is activated in basal cell carcinoma (BCC)6) Sox13 was also identified as a possible downstream target of Hedgehog signaling 7). Thus, investigating the role of Sox13 in BCC development may provide a novel molecular platform for tumorigenesis of BCC.

\section{Reference}

1) J.C. Kiefer: Dev. Dyn. 236 (2007) 2356-2361.

2) A. Sarkar, K. Hochedlinger: Cell Stem Cell. 12 (2013) 15-30.

3) V. Lefebvre: J. Biochem. Cell Biol. 42 (2010) 429-432.

4) J. Roose, et al: Nucleic Acids Res. 26 (1998) 469-476.
5) M. Noto, et al: Biochem Biophys Res Commun. (2019) 862-868.

6) V.P. Vidal, et al: Curr Biol. 15 (2005) 1340-1351.

7) O. Hallikas, et al: Cell. 124 (2006) 47-59. 